\title{
Comparable Efficacy of Idelalisib Plus Rituximab and Ibrutinib in Relapsed/refractory Chronic Lymphocytic Leukemia: A Retrospective Case Matched Study of the Polish Adult Leukemia Group (PALG)
}

\author{
BARTOSZ PUŁA ${ }^{1}$, BOŻENA KATARZYNA BUDZISZEWSKA ${ }^{1}$, JUSTYNA RYBKA ${ }^{2}$, LIDIA GIL ${ }^{3}$, \\ EDYTA SUBOCZ ${ }^{4}$, MONIKA DŁUGOSZ-DANECKA ${ }^{5}$, DARIA ZAWIRSKA ${ }^{5}$, ANNA WASZCZUK-GAJDA ${ }^{6}$, \\ ELŻBIETA ISKIERKA-JAŻDŻEWSKA ${ }^{7}$, AGNIESZKA KOPACZ ${ }^{8}$, AGNIESZKA SZYMCZYK ${ }^{9}$, JAROSŁAW CZYŻ ${ }^{10}$, \\ EWA LECH-MARAŃDA ${ }^{1,11}$, KRZYSZTOF WARZOCHA ${ }^{1}$ and KRZYSZTOF JAMROZIAK ${ }^{1}$ \\ ${ }^{1}$ Department of Hematology, Institute of Hematology and Transfusion Medicine, Warsaw, Poland; \\ ${ }^{2}$ Department of Hematology, Blood Neoplasms and Bone Marrow Transplantation, \\ Wroclaw Medical University, Wroclaw, Poland; \\ ${ }^{3}$ Department of Hematology and Bone Marrow Transplantation, \\ Karol Marcinkowski University of Medical Sciences, Poznan, Poland; \\ ${ }^{4}$ Department of Hematology, Military Institute of Medicine, Warsaw, Poland; \\ ${ }^{5}$ Department of Hematology, Jagiellonian University, Krakow, Poland; \\ ${ }^{6}$ Department of Hematology, Oncology and Internal Medicine, Medical University of Warsaw, Warsaw, Poland; \\ ${ }^{7}$ Department of Hematology, Medical University of Lodz, Copernicus Memorial Hospital, Lodz, Poland; \\ ${ }^{8}$ Department of Hematology, Specialist District Hospital, Rzeszow, Poland; \\ ${ }^{9}$ Department of Hematooncology and Bone Marrow Transplantation, Medical University of Lublin, Lublin, Poland; \\ ${ }^{10}$ Department of Hematology, Michal Kopernik University, Bydgoszcz, Poland; \\ ${ }^{11}$ Department of Hematology and Transfusion Medicine, \\ Centre of Postgraduate Medical Education, Warsaw, Poland
}

\begin{abstract}
Background/Aim: There is limited amount of data available on the comparative efficacy of ibrutinib and idelalisib, the B-cell receptor inhibitors (BCRi) newly approved for relapsed/refractory chronic lymphocytic leukemia/small lymphocytic lymphoma ( $r / r$ CLL/SLL) treatment. The aim of our study was to analyze and compare the outcomes of real-world $r / r$ CLL/SLL patients treated with these two BCRi in outside clinical trials. Patients and Methods: A comparative case matched 1:2 analysis was performed on idelalisib combined with rituximab and ibrutinib efficacy in 102 patients with $r / r$ CLL/SLL from two observational studies of the Polish Adult Leukemia Group (PALG). Results: Both therapies produced similar overall
\end{abstract}

Correspondence to: Bartosz Puła, MD, Ph.D., Department of Hematology, Institute of Hematology and Transfusion Medicine, Indiry Gandhi Str. 14, 02-776 Warsaw, Poland. Tel: +48 223496334, Fax: +48 223496335, e-mail: bartosz.pula@gmail.com

Key Words: Idelalisib, ibrutinib, B-cell receptor inhibitors, rituximab, chronic lymphocytic leukemia. response rates (idelalisib plus rituximab $76.4 \%$ and ibrutinib $72.1 \%)$. Median progression-free survival (PFS) and overall survival (OS) in both groups were not reached. Furthermore, no significant difference was observed between both BCRi regimens in regard to $P F S(H R=0.75,95 \% C I=0.30-1.86$, $p=0.55)$ and $O S(H R=0.65,95 \% C I=0.26-1.68, p=0.39)$. Conclusion: In summary, the results of this retrospective analysis suggest that idelalisib combined with rituximab and ibrutinib therapies have comparable activity in $r / r$ CLL/SLL in daily clinical practice.

Chronic lymphocytic leukemia (CLL) is the most often diagnosed leukemia in the adult patient population in the Western world accounting approximately for $25 \%$ of the newly diagnosed cases. Predominantly it affects older patients with a median age at diagnosis of 72 years $(1,2)$. The disease itself is characterized by an accumulation of Blymphocytes in bone marrow, spleen, lymph nodes and blood and is characterized by a diverse clinical course due to accumulation of various cytogenetic and molecular abnormalities $(3,4)$. From all the observed cytogenetic changes the deletion $13 q 14$, deletion $11 \mathrm{q}$, trisomy 12 and 
deletion $17 \mathrm{p} 13$ are most often diagnosed and additionally impact patients' prognosis (5). Furthermore, a complex karyotype, as well as the hypermutation status of the immunoglobulin variable heavy chain (IgHV) of the B-cell receptor (BCR) and point mutations of the TP53, NOTCH1, SF3B1, RPS15 and MYD88 genes are regarded as potent prognostic factors $(3,4)$.

Nevertheless, defects in the p53 pathway (deletion 17p13 and/or TP53 mutations) were recognized as poor prognostic factors in the majority of studies as CLL and small lymphocytic lymphoma (SLL) bearing such aberrations mostly have an aggressive clinical course and are characterized by refractoriness to chemoimmunotherapy (69). In the randomized CLL8 trial, treatment-naïve CLL cases with the deletion $17 \mathrm{p} 13$, who were treated with fludarabine, cyclophosphamide and rituximab (FCR) showed the lowest overall response rate (ORR) reaching 68\% and median progression-free survival (PFS) of only 11.3 months (10). In the MD Anderson experience, $23 \%$ of the treated cases with the $17 \mathrm{p} 13$ deletion did not respond to first-line therapy resulting in a comparably short median PFS of 14 months (11). Results of the CLL10 trial and others showed that the combination of bendamustine and rituximab (BR) is even less effective (median PFS of 8.7 months) than the FCR regimen in treatment-naïve CLL patients with p53 defects, therefore is not recommended in such patients $(2,12-14)$. Furthermore, aberrations of the p53 pathway accumulate with the next treatment regimen owing to shorter PFS, increasing refractoriness to chemoimmunotherapy and transformation to aggressive lymphoma (Richter transformation) in up to $60 \%$ of heavily pretreated CLL patients $(3,4,15,16)$.

To date, before the introduction of B-cell receptor inhibitors (BCRi), ibrutinib and idelalisib, the relapsed/refractory chronic lymphocytic leukemia/small lymphocytic lymphoma ( $\mathrm{r} / \mathrm{r}$ CLL/SLL) with p53 defects were characterized by poor outcome $(17,18)$. Both abovementioned small molecular compounds were shown to be effective in the majority of $r / r$ CLL/SLL cases, even in those characterized by p53 pathway defects. Numerous clinical trials and real-world data indicate that durable control of the disease under ibrutinib treatment is possible, however treatment rarely results in achievement of complete remissions (CR) and some reports point to the increased incidence of Hodgkin lymphoma during ibrutinib therapy (19-22).

Nevertheless, there is limited amount of data available on the comparative efficacy of newly approved ibrutinib (registration trial RESONATE) and idelalisib (registration trial Study 116) of r/r CLL/SLL treatment $(17,18)$. Although several reports concerning patients treated outside clinical trials with ibrutinib have been published recently $(21,23$, $24)$, the real-world efficacy and tolerability of combination of idelalisib with rituximab have been less well characterized (25). Interestingly, a meta-analysis using an indirect treatment comparisons (ITC) method as well as a large retrospective study have shown a significant superiority of ibrutinib as compared to idelalisib-based combinations (25, 26). In contrast, a recent meta-analysis by Pula et al. that included five randomized clinical trials evaluating idelalisibrituximab or ibrutinib for $\mathrm{r} / \mathrm{r}$ CLL, has not demonstrated any statistical difference between these two novel therapies (27).

In view of these discordant results, this retrospective study analyzes the efficacy and tolerability of idelalisib plus rituximab combination in $\mathrm{r} / \mathrm{r}$ CLL/SLL patients, and compares the results to the outcomes of patients treated with ibrutinib using a case matched 1:2 study design.

\section{Materials and Methods}

Study design and objectives. This study was based on the data acquired in two observational studies of the Polish Adult Leukemia Group (PALG) which included the majority of patients treated within compassionate use idelalisib and ibrutinib programs in Poland. Results of the PALG observational study that included 165 $\mathrm{r} / \mathrm{r}$ CLL/SLL cases treated with ibrutinib were recently reported (21). In this work, we present the results of an observational study on idelalisib-rituximab treated patients, and we compare outcomes of both types of therapy using a case matched 1:2 analysis (21).

Eligibility, treatment and criteria for response and toxicity. The compassionate access to idelalisib in Poland required fulfilling at least one inclusion criterion from idelalisib-rituximab registration trial Study 116, that were a) presence of 17 p deletion, b) failure of two or more previous treatments - at least one with a purine analogue, c) PFS interval of less than 24 months from treatment with a nucleoside analogue/bendamustine containing regimen in combination with an anti-CD20 antibody, d) failure to respond to prior chemotherapy, stable disease, or disease progression on treatment, and f) ineligibility for treatment with a purine analogue based therapy (18). An absolute neutrophil count of at least 750 cells per microliter and adequate liver and kidney function were required. Exclusion criteria included the Richter transformation, central nervous system leukemia/lymphoma and other serious uncontrolled disease. The 17p deletion was evaluated by interphase fluorescence in situ hybridization (FISH) at local laboratories. Adverse events during treatment were graded per the criteria of the National Cancer Institute Common Terminology Criteria for Adverse Events Assessment, version 4. Assessment of the treatment response was based on 2008 IWCLL Criteria (28). Objective response rate was measured as the proportion of patients achieving a partial response (PR) with lymphocytosis (PR-L) or better. The idelalisib-rituximab treatment was given according to the protocol of Study 116 (18). The inclusion and exclusion criteria to start treatment in both compassionate use programs were similar (21).

Statistical analysis. Data analysis was performed using Prism 6.0 (GraphPad, La Jolla, CA, USA). For the purpose of the case matched analysis every patient who underwent treatment with idelalisib plus rituximab was matched to two patients treated with ibrutinib controlling for age, ECOG, CLL Rai stage, 17p deletion status and number of previous lines of therapy. The unpaired $t$-test and chi2square tests were used to analyze the relevance of association of clinical parameters and to assess the differences in outcomes between 
Table I. Characteristics of patients with relapsed/refractory chronic lymphocytic leukemia (CLL) and small lymphocytic lymphoma (SLL) qualified for combined idelalisib-rituximab and ibrutinib treatment.

\begin{tabular}{|c|c|c|c|}
\hline Parameters & Idelalisib-rituximab $(\mathrm{n}=34)$ & Ibrutinib $(\mathrm{n}=68)$ & $p$-Value \\
\hline Median age (range) & $62(33-77)$ & $63.5(43-85)$ & 0.5890 \\
\hline Patient $\leq 65$ years & $24(68.6 \%)$ & $43(63.2 \%)$ & \\
\hline ECOG performance status & & & 0.0769 \\
\hline 0 & $4(11.8 \%)$ & $6(8.8 \%)$ & \\
\hline 1 & $21(61.8 \%)$ & $37(54.4 \%)$ & \\
\hline 2 & $5(14.7 \%)$ & $16(23.5 \%)$ & \\
\hline 3 & $1(2.9 \%)$ & $7(10.3 \%)$ & \\
\hline 4 & $0(0.0 \%)$ & $1(1.5 \%)$ & \\
\hline Not reported & $3(8.8 \%)$ & $1(1.5 \%)$ & \\
\hline Rai clinical stage & & & 0.7241 \\
\hline 0 -II & $11(33.3 \%)$ & $27(49.7 \%)$ & \\
\hline III-IV & $23(67.7 \%)$ & $41(60.3 \%)$ & \\
\hline Chromosome $17 \mathrm{p} 13$ deletion & & & 1.0000 \\
\hline Present & $14(41.1 \%)$ & $28(41.1 \%)$ & \\
\hline Absent & $9(26.5 \%)$ & $18(26.5 \%)$ & \\
\hline Not tested & $11(32.4 \%)$ & $22(32.4 \%)$ & \\
\hline Previous therapies & & & 0.1428 \\
\hline Median (range) & $3(1-7)$ & $3(1-10)$ & \\
\hline$>3$ lines of therapy & $14(41.1 \%)$ & $27(39.1 \%)$ & \\
\hline
\end{tabular}

both study groups. Kaplan-Meier and log-rank test were used to analyze and compare patients' PFS and overall survival (OS). A $p$ value less than 0.05 was considered statistically significant.

\section{Results}

Results of idelalisib-rituximab observational study. A total of 50 patients were qualified to the idelalisib compassionate program in Poland. Among them 34 patients (33 CLL, 1 SLL) from 10 hematology centers who started idelalisib-rituximab therapy between March 2016 and August 2017 were included in the observational study of PALG at discretion of their treating physicians. In this group, there were 19 male and 15 female patients with a median age of 62 (range $=33-77$ years) years, and after median of 3 (range=1-7) previous lines of chemotherapy (Table I). In regard to previous treatment in the idelalisib-rituximab group, all patients had been exposed to rituximab (100\%), $33(97.1 \%)$ patients had received alkylating agents, $29(85.3 \%)$ purine analogs, $24(70.6 \%)$ bendamustine $6(17.6 \%)$ high-dose methylprednisolone, 4 (11.8\%) anthracyclines, $2(5.9 \%)$ platinum compounds, while in one (2.9\%) allogeneic hematopoietic stem cell transplantation had been performed.

The median follow-up in the observational study reached 13.2 months (range $=0.26-18.0$ months). Regarding treatment response, 26 patients $(76.4 \%)$ responded to idelalisibrituximab regimen including eight patients with $(22.6 \%) \mathrm{CR}$, $13(38.3 \%)$ patients with PR and five (14.7\%) patients with PR-L. Stable disease (SD) was noted in two (5.9\%), whereas progressive disease (PD) was observed in four (11.8\%) patients. In two patients, the response could not be adequately assessed due to death in the first month of idelalisib-rituximab treatment (first received a single dose of rituximab and idelalisib developing thereafter an influenza type A pneumonia and tumor lysis syndrome (TLS), second had the treatment interrupted due to agranulocytosis and died at home). Of the analyzed factors only less advanced disease (Rai stage 0-II) was associated with increased probability of achieving CR $(p=0.0032)$. Progression of CLL during therapy was observed in four patients. All progressions occurred up to the third month of treatment, and none was of Richter transformation type. Overall, five patients died during the study. The cause of death was progressive CLL in two patients, TLS resulting in cardiac arrest in one patient, and upper respiratory tract infection in one patient. The fifth patient discontinued the treatment due to agranulocytosis and died at home due to unknown cause.

Median PFS and OS have not been reached. Estimated PFS rate at 12 -months was $82.4 \%$, whereas OS rate $84.9 \%$. Of the analyzed possible prognostic factors (patient age, ECOG, presence of B symptoms, previous lines of treatment, Rai stage, presence of $17 \mathrm{p}$ deletion) only history of more than three lines of treatment was associated with poor OS in univariate analysis $(\mathrm{HR}=6.20,95 \% \mathrm{CI}=1.01-38.03, p=0.048)$, while none of the analyzed factors influenced PFS significantly. Regarding idelalisib-rituximab combination toxicity, the most common adverse events of grade 3-4 were pneumonia (five patients, 14.7\%), diarrhea/colitis (five 
patients, $14.7 \%$ ), whereas erythrodermia, pneumonitis and TLS were noted in two patients each (5.9\%). Overall idelalisib treatment was discontinued in 10 patients $(29.4 \%)$, with pneumonia/pneumonitis being the most frequent (5 patients, $14.7 \%$ ).

Comparison of efficacy of idelalisib-rituximab and ibrutinib. Taking into account that both PALG observational studies had similar inclusion criteria, the results of idelalisib-rituximab treatment were compared to those observed in the group of 1:2 matched cases receiving ibrutinib monotherapy (21). The baseline characteristics of patients treated with idelalisibrituximab and ibrutinib were comparable as shown in Table I. Ibrutinib monotherapy cohort consisted of 37 males and 31 females with median age of 63.5 years (range $=43-85$ years), and a median of 3 (range $=1-10$ ) previously administered lines of chemotherapy (Table I). Treatment regimens comprised of rituximab $(63 ; 92.6 \%)$, alkylating agent $(62 ; 91.2 \%)$, purine analogs $(54 ; 79,4 \%)$, bendamustine $(33 ; 48.5 \%)$, high-dose methylprednisolone $(14 ; 20.5 \%), 4(11.8 \%)$ anthracyclines $(18 ; 26.4 \%)$, alemtuzumab $(5 ; 7.4 \%)$. One $(1.4 \%)$ patient underwent allogeneic hematopoietic stem cell transplantation. Ibrutinib monotherapy generated responses in $49(72.1 \%)$ patients, of which best responses were as follows: $8(11.8 \%)$ CR, 27 (39.7\%) PR, 14 (20.6\%) PR-L. In the remaining patients $14(20.6 \%)$ SD and three (4.4\%) PD were noted, however in two patients $(2.9 \%)$ assessment of response could not be performed due to adverse events resulting in early ibrutinib discontinuation. In the analyzed cohort, the median follow-up was 9.23 (range=1.13-17.53 months) months in which 16 patients discontinued ibrutinib therapy (six due to progressive disease and ten to adverse events). Overall 15 deaths were noted. Median PFS and OS have not been reached. Estimated PFS rate at 12-months was $77.6 \%$, whereas OS rate $74.5 \%$.

Statistical analysis revealed that the ORR was very similar for both types of therapy, e.g. 76.4\% with idelalisib-rituximab and $72.1 \%$ with ibrutinib treatment. Of note, $\mathrm{CR}$ rate achieved in the idelalisib cohort seemed to be higher (22.6\%) compared to the ibrutinib cohort $(11.8 \%)$, however the difference was not statistically significant $(p=0.15)$. Interestingly, in contrast to some previous observations, significant differences were not identified between both BCRi regimens in regard to PFS $(\mathrm{HR}=0.75,95 \% \mathrm{CI}=0.30-1.86, p=0.55)$. Furthermore, $\mathrm{OS}$ in both cohorts of patients was comparable (HR=0.65, $95 \% \mathrm{CI}=0.26-1.68, p=0.39)$. The survival curves for PFS and OS in both patients' groups are shown in Figure 1.

\section{Discussion}

In this retrospective analysis, the activity of the combination of idelalisib with rituximab regimen used in real-world $r / r$ CLL/SLL patients was found to be satisfactory and
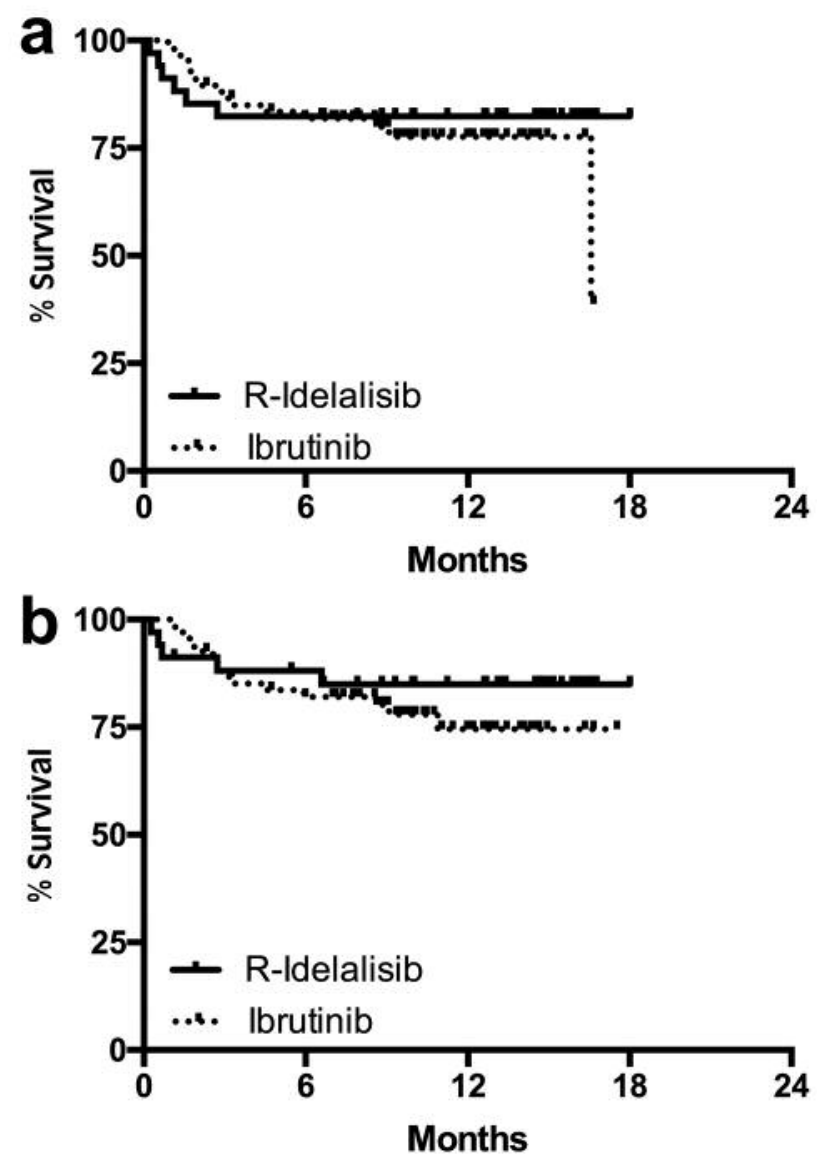

Figure 1. Kaplan-Meier curves of progression-free survival (PFS, a) and overall survival $(O S, b)$ of the rituximab-idelalisib (R-idelalisib) and ibrutinib compassionate use program cohorts (21).

comparable to that of ibrutinib monotherapy. The obtained results indirectly support the findings of recent meta-analysis that did not show significant differences between outcomes of idelalisib and ibrutinib containing regimens administered within five randomized clinical trials (27).

In our observational idelalisib cohort comparable results to those in the idelalisib-rituximab cohort of Study 116 in terms of ORR $(76.4 \% v s .81 \%)$ and rate of 12 -month OS rate ( $84.9 \%$ vs. 92\%) were noted (17). It should be underlined that although ORR to idelalisib-rituximab in our study is similar to those observed in the Study 116 and observational study of Mato et al. (ORR 80\%) $(18,25)$, a significantly higher CR rate of $22.6 \%$ was found as compared to the above-mentioned studies. Six out of eight of these cases were of Rai stage I or II and received less than three lines of treatment prior to rituximab-idelalisib treatment which may partially explain such high CR rate. Nevertheless, the rate of Rai III-IV cases and median of previous lines of treatment between our study and that of the Study 116 was comparable (18). Furthermore, 
some differences in the adverse events profile were noted.

Analysis of the toxicity profile of our treated patients' receiving idelalisib-rituximab therapy identified pneumonia and diarrhea as the most common grade 3-4 adverse events, of which pneumonia/pneumonitis were the most frequent causes of treatment discontinuation. Interestingly, none of the patients discontinued the treatment due to diarrhea or colitis, which were reported to be one of major causes of idelalisib discontinuation in the Study $116(2.7 \%)$ and the observational study of Mato et al. (9.6\%) (18, 25). Furthermore, the typical idelalisib related transaminitis occurred only in one patient and was of grade 1. Beside a single case of CMV reactivation, a significant rise in opportunistic infection occurrence was not noted.

In contrast to our results, some other studies demonstrated superiority of ibrutinib over idelalisib-rituximab in $\mathrm{r} / \mathrm{r}$ CLL $(25,27)$. Of note, a comparative analysis by Mato et al. (25), reported similar initial response rate to ibrutinib and idelalisib, however further follow-up revealed that PFS was significantly shorter with idelalisib (11 months) as compared to the ibrutinib treated patients (36 months). Such relationship was not observed in our comparative analysis. The good results obtained in this study from treatment with idelalisib, including the high CR rate, could be partially explained by relatively less advanced disease stages and good fitness in this group of patients. This theoretically more treatment sensitive patients' profile may also partially explain the longer duration of PFS achieved with idelalisib-rituximab in our observational study as compared to the one reported by Mato et al. (25). However, it cannot be excluded that some differences in respect of PFS between ibrutinib and idelalisib-rituximab treated cohorts become visible with additional follow-up time (Figure 1).

In conclusion, in real-world patients with $\mathrm{r} / \mathrm{r}$ CLL/SLL idelalisib-rituximab therapy has efficacy comparable to ibrutinib and acceptable toxicity.

\section{Conflicts of Interest}

The Authors state that they have no conflicts of interest in regard to this study.

\section{Acknowledgements}

This study was supported by the scientific grant of National Science Centre in Poland, no. UMO-2016/21/D/NZ5/02569. The Authors express their gratitude to treating physicians and members of PALG participating in compassionate use programs of idelalisib and ibrutinib in Poland.

\section{References}

1 Redaelli A, Laskin BL, Stephens JM, Botteman MF and Pashos CL: The clinical and epidemiological burden of chronic lymphocytic leukaemia. Eur J Cancer Care (Engl) 13: 279-287, 2004.
2 Eichhorst B, Robak T, Montserrat E, Ghia P, Hillmen P, Hallek $\mathrm{M}$ and Buske $\mathrm{C}$ : Chronic lymphocytic leukaemia: ESMO Clinical Practice Guidelines for diagnosis, treatment and followup. Ann Oncol 26: v78-84, 2015.

3 Landau DA, Carter SL, Stojanov P, McKenna A, Stevenson K, Lawrence MS, Sougnez C, Stewart C, Sivachenko A, Wang L, Wan Y, Zhang W, Shukla SA, Vartanov A, Fernandes SM, Saksena G, Cibulskis K, Tesar B, Gabriel S, Hacohen N, Meyerson M, Lander ES, Neuberg D, Brown JR, Getz G and Wu CJ: Evolution and impact of subclonal mutations in chronic lymphocytic leukemia. Cell 152: 714-726, 2013.

4 Landau DA, Tausch E, Taylor-Weiner AN, Stewart C, Reiter JG, Bahlo J, Kluth S, Bozic I, Lawrence M, Bottcher S, Carter SL, Cibulskis K, Mertens D, Sougnez CL, Rosenberg M, Hess JM, Edelmann J, Kless S, Kneba M, Ritgen M, Fink A, Fischer K, Gabriel S, Lander ES, Nowak MA, Dohner H, Hallek M, Neuberg D, Getz G, Stilgenbauer S and Wu CJ: Mutations driving CLL and their evolution in progression and relapse. Nature 526: 525-530, 2015.

5 Dohner H, Stilgenbauer S, Benner A, Leupolt E, Krober A, Bullinger L, Dohner K, Bentz M and Lichter P: Genomic aberrations and survival in chronic lymphocytic leukemia. $\mathrm{N}$ Engl J Med 343: 1910-1916, 2000.

6 Zenz T, Eichhorst B, Busch R, Denzel T, Habe S, Winkler D, Buhler A, Edelmann J, Bergmann M, Hopfinger G, Hensel M, Hallek M, Dohner H and Stilgenbauer S: TP53 mutation and survival in chronic lymphocytic leukemia. J Clin Oncol 28: 4473-4479, 2010.

7 Zenz T, Habe S, Denzel T, Mohr J, Winkler D, Buhler A, Sarno A, Groner S, Mertens D, Busch R, Hallek M, Dohner H and Stilgenbauer S: Detailed analysis of p53 pathway defects in fludarabine-refractory chronic lymphocytic leukemia (CLL): dissecting the contribution of $17 \mathrm{p}$ deletion, TP53 mutation, p53p21 dysfunction, and miR34a in a prospective clinical trial. Blood 114: 2589-2597, 2009.

8 Zenz T, Vollmer D, Trbusek M, Smardova J, Benner A, Soussi T, Helfrich H, Heuberger M, Hoth P, Fuge M, Denzel T, Habe S, Malcikova J, Kuglik P, Truong S, Patten N, Wu L, Oscier D, Ibbotson R, Gardiner A, Tracy I, Lin K, Pettitt A, Pospisilova S, Mayer J, Hallek M, Dohner $\mathrm{H}$ and Stilgenbauer S: TP53 mutation profile in chronic lymphocytic leukemia: evidence for a disease specific profile from a comprehensive analysis of 268 mutations. Leukemia 24: 2072-2079, 2010.

9 Diamantopoulos PT, Samara S, Kollia P, Giannakopoulou N, Sofotasiou M, Kalala F, Kodandreopoulou E, Zervakis P, Vassilakopoulos T, Siakantaris M, Mantzourani M, Angelopoulou M, Kyrtshonis MC, Korkolopoulou P, Patsouris E and Viniou NA: Tumor protein 53 gene mutations without $17 \mathrm{p} 13$ deletion have no significant clinical implications in chronic lymphocytic leukemia. Detection of a new mutation. Anticancer Res 37: 2387-2391, 2017.

10 Hallek M, Fischer K, Fingerle-Rowson G, Fink AM, Busch R, Mayer J, Hensel M, Hopfinger G, Hess G, von Grunhagen U, Bergmann M, Catalano J, Zinzani PL, Caligaris-Cappio F, Seymour JF, Berrebi A, Jager U, Cazin B, Trneny M, Westermann A, Wendtner CM, Eichhorst BF, Staib P, Buhler A, Winkler D, Zenz T, Bottcher S, Ritgen M, Mendila M, Kneba $\mathrm{M}$, Dohner $\mathrm{H}$ and Stilgenbauer S: Addition of rituximab to fludarabine and cyclophosphamide in patients with chronic lymphocytic leukaemia: a randomised, open-label, phase 3 trial. Lancet 376: 1164-1174, 2010. 
11 Strati P, Keating MJ, O’Brien SM, Ferrajoli A, Burger J, Faderl S, Tambaro FP, Jain N and Wierda WG: Outcomes of first-line treatment for chronic lymphocytic leukemia with $17 \mathrm{p}$ deletion. Haematologica 99: 1350-1355, 2014

12 Eichhorst B, Fink AM, Bahlo J, Busch R, Kovacs G, Maurer C, Lange E, Koppler H, Kiehl M, Sokler M, Schlag R, VehlingKaiser U, Kochling G, Ploger C, Gregor M, Plesner T, Trneny M, Fischer K, Dohner H, Kneba M, Wendtner CM, Klapper W, Kreuzer KA, Stilgenbauer S, Bottcher S and Hallek M: First-line chemoimmunotherapy with bendamustine and rituximab versus fludarabine, cyclophosphamide, and rituximab in patients with advanced chronic lymphocytic leukaemia (CLL10): an international, open-label, randomised, phase 3, non-inferiority trial. Lancet Oncol 17: 928-942, 2016.

13 Kleeberg UR, Linde H, Gunther G, Tessen HW and Kersting M: Bendamustin-rituximab combination is a safe and effective, ambulatory treatment for elderly patients with chronic lymphocytic leukemia: Retrospective real-world analysis by age from a german registry and review of the literature. Anticancer Res 36: 2827-2838, 2016.

14 Eichhorst B, Robak T, Montserrat E, Ghia P, Hillmen P, Hallek $\mathrm{M}$ and Buske C: appendix 6: Chronic lymphocytic leukaemia: eUpdate published online September 2016 (http://www.esmo. org/Guidelines/Haematological-Malignancies). Ann Oncol 27: v143-v144, 2016.

15 Fabbri G and Dalla-Favera R: The molecular pathogenesis of chronic lymphocytic leukaemia. Nat Rev Cancer 16: 145-162, 2016.

16 Jamroziak K, Tadmor T, Robak $\mathrm{T}$ and Polliack A: Richter syndrome in chronic lymphocytic leukemia: updates on biology, clinical features and therapy. Leuk Lymphoma 56: 1949-1958, 2015.

17 Byrd JC, Brown JR, O’Brien S, Barrientos JC, Kay NE, Reddy NM, Coutre S, Tam CS, Mulligan SP, Jaeger U, Devereux S, Barr PM, Furman RR, Kipps TJ, Cymbalista F, Pocock C, Thornton P, Caligaris-Cappio F, Robak T, Delgado J, Schuster SJ, Montillo M, Schuh A, de Vos S, Gill D, Bloor A, Dearden C, Moreno C, Jones JJ, Chu AD, Fardis M, McGreivy J, Clow F, James DF and Hillmen P: Ibrutinib versus ofatumumab in previously treated chronic lymphoid leukemia. N Engl J Med 371: 213-223, 2014.

18 Furman RR, Sharman JP, Coutre SE, Cheson BD, Pagel JM, Hillmen P, Barrientos JC, Zelenetz AD, Kipps TJ, Flinn I, Ghia P, Eradat H, Ervin T, Lamanna N, Coiffier B, Pettitt AR, Ma S, Stilgenbauer S, Cramer P, Aiello M, Johnson DM, Miller LL, Li D, Jahn TM, Dansey RD, Hallek M and O'Brien SM: Idelalisib and rituximab in relapsed chronic lymphocytic leukemia. N Engl J Med 370: 997-1007, 2014.

19 Jamroziak K, Pula B and Walewski J: Current treatment of chronic lymphocytic leukemia. Curr Treat Options Oncol 18: 5, 2017.

20 Jamroziak K, Szymczyk A, Hus M, Wojciechowska M, Knopinska-Posluszny W, Holojda J, Halaburda K, Warzocha K and Iskierka-Jazdzewska E: Hodgkin's variant of Richter's transformation during ibrutinib therapy in a series of CLL patients; the Polish Adult Leukemia Group report (PALG). Eur J Haematol 100: 389-391, 2017.
21 Iskierka-Jazdzewska E, Hus M, Giannopoulos K, Madro E, Holojda J, Piotrowska M, Zaucha JM, Piszczek W, Szeremet A, Wojciechowska M, Steckiewicz P, Knopinska-Posluszny W, Osowiecki M, Drozd-Sokolowska J, Kumiega B, KyrczKrzemien S, Halka J, Dudzinski M, Wieszczy P, Robak T, Warzocha $\mathrm{K}$ and Jamroziak $\mathrm{K}$ : Efficacy and toxicity of compassionate ibrutinib use in relapsed/refractory chronic lymphocytic leukemia in Poland: analysis of the Polish Adult Leukemia Group (PALG). Leuk Lymphoma: 1-4, 2017.

22 Sachanas S, Pangalis GA, Moschogiannis M, Yiakoumis X, Koulieris E, Tsirkinidis P, Kalpadakis C and Rontogianni D: Hodgkin lymphoma transformation of chronic lymphocytic leukemia under ibrutinib therapy: Chance association or therapyrelated? Anticancer Res 37: 3277-3280, 2017.

23 Winqvist M, Asklid A, Andersson PO, Karlsson K, Karlsson C, Lauri B, Lundin J, Mattsson M, Norin S, Sandstedt A, Hansson $\mathrm{L}$ and Osterborg A: Real-world results of ibrutinib in patients with relapsed or refractory chronic lymphocytic leukemia: data from 95 consecutive patients treated in a compassionate use program. A study from the Swedish Chronic Lymphocytic Leukemia Group. Haematologica 101: 1573-1580, 2016.

24 Forum UC: Ibrutinib for relapsed/refractory chronic lymphocytic leukemia: a UK and Ireland analysis of outcomes in 315 patients. Haematologica 101: 1563-1572, 2016.

25 Mato AR, Hill BT, Lamanna N, Barr PM, Ujjani CS, Brander DM, Howlett C, Skarbnik AP, Cheson BD, Zent CS, Pu JJ, Kiselev P, Foon K, Lenhart J, Henick Bachow S, Winter AM, Cruz AL, Claxton DF, Goy A, Daniel C, Isaac K, Kennard KH, Timlin C, Fanning M, Gashonia L, Yacur M, Svoboda J, Schuster SJ and Nabhan C: Optimal sequencing of ibrutinib, idelalisib, and venetoclax in chronic lymphocytic leukemia: results from a multicenter study of 683 patients. Ann Oncol 28: 1050-1056, 2017.

26 Sorensen S, Wildgust M, Sengupta N, Trambitas C, Diels J, van Sanden S, Xu Y and Dorman E: Indirect treatment comparisons of ibrutinib versus physician's choice and idelalisib plus ofatumumab in patients with previously treated chronic lymphocytic leukemia. Clin Ther 39: 178-189.e175, 2017.

27 Pula A, Stawiski K, Braun M, Iskierka-Jazdzewska E and Robak T: Efficacy and safety of B-cell receptor signaling pathway inhibitors in relapsed/refractory chronic lymphocytic leukemia: a systematic review and meta-analysis of randomized clinical trials. Leuk Lymphoma: 1-11, 2017.

28 Hallek M, Cheson BD, Catovsky D, Caligaris-Cappio F, Dighiero G, Dohner H, Hillmen P, Keating MJ, Montserrat E, Rai KR and Kipps TJ: Guidelines for the diagnosis and treatment of chronic lymphocytic leukemia: a report from the International Workshop on Chronic Lymphocytic Leukemia updating the National Cancer Institute-Working Group 1996 guidelines. Blood 111: 5446-5456, 2008.

Received March 18, 2018

Revised April 5, 2018

Accepted April 10, 2018 